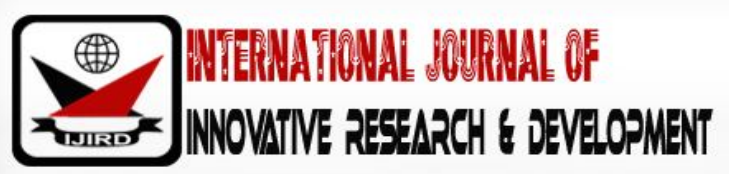

ISSN 2278 - 0211 (Online)

\section{Payment System Innovations and Economic Growth: An Empirical Study of the BRINCS Countries}

\author{
Dumbor C. Bulo \\ Ph.D. Scholar, Department of Finance and Banking, University of Port Harcourt, Nigeria
}

\begin{abstract}
:
The study examines whether the economic growth of emerging market economies of Brazil, Russia, India, China, Nigeria and South-Africa are influenced by country-specific policies and strategies regarding payment systems using the fixed effects approach under the panel date framework. The results show that all the three payment channels considered (ATM, POS, and $\mathrm{ACHC}$ ) have the expected positive signs, suggesting that that payment system innovation enhances economic activities and leads to higher economic growth in emerging countries. However, the magnitude of the impact of e-payment channels (ATM and POS) is quite substantial compared to the traditional cheque. The coefficient on Cheque is very low and insignificant, implying a possible crowd out of e-payments against the traditional cheque. The results also confirm the presence of unobserved heterogeneity in the panel data, with the country-specific fixed effects showing significant differences in payment system policies and strategies across the BRINCS countries. Thus, the study concludes that both payments system innovation and the cross-sectional fixed effects have high explanatory power for economic growth in emerging market economies.
\end{abstract}

Keywords: Payment system, emerging markets, economic growth

\section{Introduction}

Emerging market economies has been predominantly cash-based but now increasingly moving towards electronic owing to financial innovation. Most countries' payments system is gradually being transformed from paper and cheque to electronic based payments (Hossein \& Jaberi, 2009). This improvements in payment system offers a variety of facilities to use rather than handling cash physically (De Rose, 2017), encourage the move from cash holding to demand deposit holding thus extended credit (Ouarda \& Erlend, 2009), thereby promotes consumption, trade and overall growth (Hasan, De Renzis \& Schmiedel, 2012). Therefore, innovation in payments system is a necessary condition in assessing the growth and development level of a market economy.

The essence of financial innovation is for increase efficiency in financial transactions and intermediation aim at enhancing productivity. Berger (2003)notes that like electronic payment and information exchange technologies, technological innovations in a financial system, significantly enhance productivity due to bank's services improvements resulting to increases in productivity and economies of scale. Specifically, aside from individual financial empowerment, integrating electronic payment options into emerging economies and developing nations will lead to broad economic growth (World Bank, 2014). However, giving the low GDP per capita with ravaging poverty of emerging market economies, integrating/ increasing electronic payment system seem not to have lead to broad economic growth.

Theoretically, because every economic activity passes through the financial system, financial innovations contribute majorly to the economic growth process.There is agreement that among scholars and practitioners that market forces provide the best mechanism for resource allocation. This therefore, implies that the level of financial system innovations of any country should affect her economic growth, with the same effect expected on the countries belonging to the same economic block.

The aim of this study is to examine how innovations in payment systems influence economic growth of emerging market economies under a panel data framework. The study also seeks to determine whether the economic growth of Brazil, Russia, India, China, Nigeria and South-Africa are influenced by country-specific policies and strategies regarding payment systems. The rest of the study is organized into four sections. The next section contains the literature review while methodology and empirical analysis are contained in sections three and four. Chapter five concludes the study. 


\section{Literature Review}

\subsection{Diffusion of Innovation Theory (DOI)}

Diffusion of innovation Theory (DOI) posits that acceptance of new idea or innovation is due to interaction among individuals in the course of interpersonal networks. Therefore, in our context, diffusion is the increase in electronic payments system following institutional (businesses) quest for new profit opportunities as well as consumer's yearning for improved and convenient transaction experience. Diffusion of electronic payments system will result in cashless transactions option adoption within the society subject to innovative payment system adopters and the process of innovation decision making. Therefore, since the consequence of electronic payment system diffusion depends on the swiftness of society's willingness in adopting electronic payment system throughout various stages of innovation procedure, its adoption impact will differ in different society. Roger in 1962 first introduced this concept when he explains how innovation is spread to those within a social system over time (Rogers, 1995). We want to see innovation in payment system impacts on economic progress of emerging market economies.

\subsection{Endogenous Growth Theory}

Traditionally, growth is viewed as a continuum and finance plays no role, however there are actual variations in growth that could be clarified by finance giving the savings-investment-growth link. Financial system is crucial in understanding these discontinuous-variations in growth (Allen \& Oura, 2004). Caporale, Howells and Soliman (2004) put forward that the Endogenous Growth Theory advocates that the performance of the economy is related with level or degree of financial development, technology, innovations and income sharing. In their model, Greenwood and Jovanovic (1990) presumes that the link connecting financial development to growth is positive and mutually contributory which allows probing income distribution-growth nexus, and financial structure-economic development link. First, financial institutions identify opportunities for investment with maximum returns and direct resources towards the best profitable option thus enhancing investment and growth. Second, in reciprocation, growth provides the resources requisite to grow and execute expensive financial arrangement through innovation. This position was collaborated by King and Levine (1993), when they identified innovation as growth driver. They based their argument on the credence that allocating funds efficiently to entrepreneurs by financial mediators is capable of lowering investment cost and enhances output through innovation in so doing stimulating economic expansion.

Therefore, there may be positive influence of innovation in payment system on economic progress in the long-run. Nevertheless, though expanded financial services-output growth link is long-run Positive, the association is mostly short-run negative (Loayza \& Ranciere, 2006). Demetriades and Law (2006) however observed that positive relationship can only hold in economies characterized by strong institutions and regulatory framework. This theory helps us to measure the interrelationship between innovation in financial services and economic growth.

\subsection{Review of Empirical Studies}

Spurred by the apparent reluctance in accepting and executing Nigeria's cashless policy, Okoye, and Ezejiofor (2013) examines the considerable benefits and vital components in Nigeria's cashless policy to ascertain degree to which it can enhance growth of financial stability in the country. With 68 sample size using convenience sampling technique, the study adopts descriptive study design. The study collects data via well-structured questionnaire and subjects to validity test with ANOVA and chi-square $\left(\mathrm{X}^{2}\right)$ technique. The results show a high level of the policy awareness among Nigerians with majority agreeing on the potency of the policy in the anti-corruption fight, money laundering in addition reduction in risks associated in carrying cash. The study correspondingly predicts cyber fraud and illiteracy as the foremost problems that will hamper the cashless policy implementation. They conclude that for the implementation of the policy to be successful, government must adopt diverse approach in enlightening non-literate Nigerians concerning cashless economy and institute framework for cyber security in Nigeria.

Using survey instrument with dual class of respondents (customers and managers) on randomly chosen 550 samples from the carefully chosen retail outlets, Wali, Wright, and Reynolds (2014) examines how the non-cash system affects customer's view and the Nigeria retailing sector marketing feat. The study established a positive impact of both cashless system measures on retail marketing performance measures on one hand and consumers perception of the innovative method as disadvantageous in the short term but with long-term benefits. They conclude that in agreement with global banking best practices, the cashless system would decrease huge outlay for retail business as it relate to erudite workforce, and security besides boosting Nigeria's retail investments prospects. They recommend the apex Bank collaboration with deposit money banks and telecoms firms to mitigate the negative electronic platforms clients' buy experiences.

Slozko, and Pelo, (2014), analyze innovation in financial market and its overall consequences for the global economy. The study uses correlation analysis to show statistically the connection linking economic growth to increasing e-payment. The result reveals correlation between e-payment increasing and GDP growth indicating that diffusion of electronic payments causes increase consumption, thus, contributes to accelerate economic development. 
Norden, Buston and Wagner (2014) found that manages an account with bigger gross positions in credit subordinates charge altogether bring down corporate advance spreads, while banks net positions are not reliably identified with advance estimating. They contended this is steady with banks passing on chance administration advantages to corporate borrowers however not with elective channels through which credit subsidiary utilize may influence advance evaluating. They additionally found that the size of the hazard administration impact stayed unaltered amid the emergency time frame. Likewise, keeps money with bigger gross positions in credit subordinates cut their loaning by not as much as different banks amid the emergency and have reliably bring down advance charge-offs. Their investigation is suggestive of noteworthy hazard administration profits by budgetary advancements that endure under unfriendly conditions, that is, the point at which they matter most.

In trying to ascertain if innovation financial services is essential in sustaining economic growth, Laeven, Levine, and Michalopoulos (2015) construct a Schumpeterian model wherein entrepreneurs earn profits by creating superior products while profit seeking financial institutions come up to scrutinize entrepreneurs. Their model reveals two distinct elements. Firstly, the processes of innovation engaged by financiers are expensive although potentially money-spinning as they can devise superior entrepreneurs selection techniques. Secondly, technology advancement renders all selection technique ineffectual. They therefore predict that if financiers do not innovate, hi-tech innovation as well as economic growth will discontinue in the long-run.

Dunne and Kasekende (2016) investigate 34 countries from 1980 to 2013 through panel data methodology to probe the progress of innovation in finance and how it affects Sub-Saharan Africa money demand. The outcome indicates financial innovation negatively relates to money demand. Their conclusion was that financial innovation significantly explains subSaharan Africa money demand behave our thus is capable of having substantial implications for future policy blueprint.

\section{Methodology}

\subsection{Data}

We use a relatively long panel data $(N<T)$ consisting of the six emerging countries that form the BRINCS countries (Brazil, Russia, India, Nigeria, China and South Africa). The data are measured at yearly frequency, covering a period of ten years from 2006 to 2015. The innovative payment system variables considered are automated Cheque payment (ACHC), point of sale payment (POS), automated teller machines payment (ATM) while economic growth is proxied by real gross domestic product (RGDP). The source of data is the International Bank for Reconstruction and Development (IBRD) World Development Indicator (WDI).All data are converted into logarithm before subjecting them for empirical analysis using EViews 9.

\subsection{Method}

Regression analysis involving panel data is usually based on three equal but competing models; pooled least square model (PLSM), the fixed effects model (FEM) and the random effects model (REM). For PLSM, the panel data is structured and pooled as time series with no regards to the cross-sectional dimension of the data. The assumption for pooling the data together is that even though cross-sectional differences are always present in panel data, such heterogeneity is independent and cannot significantly influence the main relationships of interest. This restriction is also the main limitation of the pooled least square approach.Both FEM and FEM recognize that some important (cross-sectional) heterogeneity may be hidden in the panel data and if ignored, will lead to heterogeneity bias which is a serious specification problem in any panel data model.However,they disagree on how this heterogeneity can be modeled. On the one hand, the fixed effect model allows the intercept term to vary to reflect the cross-sectional differences, with the assumption that each cross-sectional intercept correlates with the main regressors. On the other hand, the random effects model captures the cross-sectional heterogeneity in the error term by assuming that each cross-sectional specific term is a random deviation from a common intercept that does not correlate with the main regressors. The earlier study by Bulo and Nwakanma (2017) on payment system-growth relationship in the BRINCS countries was based on the random effects model. The authors argued that financial innovations are a global trend and any country specific deviation from this trend should be treated as independent and random. However, this studyassumes that each cross-sectional specific term is likely to influence its payment system strategies and policies. Thus, we employ the fixed effects model to examine the payment system-growth relationships.

\subsection{Fixed Effects Model Specification}

The fixed effects model connecting economic performance to financial innovations (payment channels) is given by:

$L R G D P_{i t}=\theta+\lambda_{i}+\beta_{1} L_{A C H C}+\beta_{2} L_{P O S_{i t}}+\beta_{3} L_{A T M}+\epsilon_{i t}$

where; $\theta$ is the regression intercept, $\lambda_{i}=$ the country-specific parameter that captures cross-sectional heterogeneity, $\beta_{i}$ are the time-invariant beta coefficients for the relationships of interest and $\epsilon_{i t}$ is the error term. If $\lambda_{i}$ is absorbed in $\theta$, the fixed effects model at (1) can be rewritten as:

$\operatorname{LRGDP}_{i t}=\theta_{i}+\beta_{1}$ LACHC $_{i t}+\beta_{2}$ LPOS $_{i t}+\beta_{3} L_{A T M} M_{i t}+\epsilon_{i t}$ 
where; $\theta_{i}\left(=\theta+\lambda_{i}\right)$ varyonly cross-sectionally so that each $\theta_{i}$ accounts for each country's specific characteristics relative to its payment system. The fixed effects model can be estimated using the Least Square Dummy Variable (LSDV) technique.

\section{Empirical Analysis}

Table 1 shows the estimation results for the fixed effects model using the LSDV approach. To avoid the problem of perfect multi-collinearity or dummy variable trap, we include a constant and five dummies since we have six countries in the regression model. The five dummy variables represent Brazil, Russia, India, China and South Africa. Nigeria is used as reference or benchmark country for easy comparison, and thus, there is no dummy variable representing Nigeria. We assign 1 to the dummy variable for Brazil if the observation belongs to Brazil, and 0 otherwise. Similarly, dummy for Russia equals 1, if the observation belongs to Russia, and equals 0 otherwise; dummy for India equals 1 if the observation is for India, and equals 0 otherwise; dummy for China equals if the observation is for China, and equals zero otherwise; dummy for South Africa equals 1 if the observation is for South Africa, and equals 0 otherwise. The intercept term represents Nigeria and is used to compare the performance of other countries. Thus, dummies for other countries are evaluated relative to Nigeria.

From table 1, the estimated fixed effects model has a near perfect fit and the overall regression is highly significant as evidenced by the value of the adjusted R-square, which is very close to 1 at 0.993 , and the F-statistic which is associated with a zero probability. Despite that value the Durbin -Watson statistic is low at 0.683 , the estimatedfixed effects model seems to be well-behaved as the Jarque-Bera statistic fails to reject the normality of residual hypothesis atall reasonable significance levels. In terms of the main effects, the beta estimates for the three payment channels all have the expected positive signs, with LATM (beta $=0.244$ ) having the highest coefficient in terms of magnitude, followed by LPOS (beta $=0.170$ ), and then by LACHC(beta $=0.0003$ ). Thus, all the payment channels have positive relationship with economic growth, showing that payment system innovations enhance economic activities and lead to higher economic growth in emerging countries. However, while both Automated Teller Machine and Point of Sale terminal show highly significant effects ( $p$-value $=0.0000$ ), Cheque shows insignificant effect ( $\mathrm{p}$-value $=0.8488$ ). This implies that e-payment channels (ATM and POS) have more influence on economic activities in emerging countries than the use of Cheque. This is expected given that payment of goods and services via e-payment channels tend to crowd out the irdated alternatives such as Cheque. The more e-payment platforms are introduced, the less the use of older platforms that typically involve physical interactions with banks and this might not be unrelated with the delays associated with such interactions in the emerging market.

For the country specific fixed effects, table 1 show that all the estimated dummies are highly significance, confirming the presence of unobserved heterogeneity in our panel data. Thus, consistent with the fixed effects model assumption, the differences in the estimated intercept dummies reflect the differences in the BRINCS countries in terms of payment system strategies and policies. The country-specific values for the six countries statistically different, being 8.609557 for Nigeria (the intercept term), $5.574657(=8.609557$ - 3.030490) for Brazil, 7.3461 (= 8.609557 - 1.263457) for Russia, 7.741973 (= 8.609557 - 0.867584) for India, $6.786489(=8.609557$ - 1.823068) for China, 5.315827 (= 8.609557 - 3.293730) for South Africa. The cross-sectional fixed effects is thus, given in table 2.

\begin{tabular}{|c|c|c|c|}
\hline Variable & \multicolumn{2}{|c|}{ Beta } & Prob. \\
\hline Constant (Nigeria) & \multicolumn{2}{|c|}{8.609557} & 0.0000 \\
\hline Brazil & \multicolumn{2}{|c|}{-3.030490} & 0.0000 \\
\hline Russia & \multicolumn{2}{|c|}{-1.263457} & 0.0000 \\
\hline India & \multicolumn{2}{|c|}{-0.867584} & 0.0000 \\
\hline China & \multicolumn{2}{|c|}{-1.823068} & 0.0000 \\
\hline South Africa & \multicolumn{2}{|c|}{-3.293730} & 0.0000 \\
\hline LPOS & \multicolumn{2}{|c|}{0.170445} & 0.0000 \\
\hline LATM & 0.244565 & & 0.0000 \\
\hline $\mathrm{LACHC}$ & 0.003340 & \multicolumn{2}{|c|}{0.8488} \\
\hline R-squared & 0.994215 & Durbin-Watson stat & 0.683566 \\
\hline Adj. R-squared & 0.993289 & Jarque-Bera (JB) & 0.782239 \\
\hline F-statistic & $1074.060 \quad 0.000)$ & Prob(Jarque-Bera) & 0.676299 \\
\hline
\end{tabular}

Table 1: Random Effects results; ( ) contains p-value Source: E-view output 


\begin{tabular}{|c|c|c|}
\hline S/ No & Country & Fixed effects \\
\hline 1 & Nigeria & 8.6095 \\
\hline 2 & Brazil & 5.5746 \\
\hline 3 & Russia & 7.3461 \\
\hline 4 & India & 7.7419 \\
\hline 5 & China & 6.7864 \\
\hline 6 & South Africa & 5.3158 \\
\hline
\end{tabular}

Table 2: Cross-Sectional Fixed Effects

Source: Self Computed From Fixed Effects Results

\section{Conclusions}

In this paper, we investigate the relationship between payment system innovations and economic growth for BRINCS countries under the framework of panel data. The BRINCS countries are block of emerging countries consisting of Brazil, Russia, India, China, South Africa and Nigeria. The payment system innovations are proxied by three payment channels; namely, the value of Cheque transactions, the value of transactions through ATMand the value of transaction through POS. The study covers a period of ten years from 2006 to 2015.

There is evidence that the three payment system variables have a positive relationship with economic growth showing that payment system innovations enhance economic activities and lead to higher economic growth in emerging countries. However, the effect of Cheque is very much lower than that of both ATM and POS, and is not significant. The model is well-behaved, and the overall regression is highly significant, showing that the payment system innovations have high explanatory power for economic growth. The cross-sectional fixed effects are also found to be significantly related to economic growth, confirming the presence of heterogeneity in the BRINCS data.

Overall, the results support the view that innovations in payment systems lead to higher economic growth. The results therefore, provide empirical support for the view that finance development precedes growth. These findings also agree with most of the previous findings including Hasan, De Renzis, and Schmiedel (2012), Slozko, and Pelo, (2014), Laeven, Levine, and Michalopoulos (2015), Moody's Analytics (2016), and Bulo and Nwakanma (2017).

\section{References}

i. Allen, F., \& Oura, H. (2004). Sustained Economic Growth and the Financial System. IMES Discussion Paper Series 2004E -17, August 2004.

ii. Berger A. N. (2003). The economic effects of technological progress: Evidence from the banking industry. Journal of Money Credit and Banking, 35, 141-176.

iii. Bulo, D. C. \& Nwakanma, P. C. (2017).........................................................

iv. Caporale, G. M., Howells, P., \& Soliman, A. M. (2004). Endogenous growth models and stock development: Evidence from four countries. Review of Development Economics, 9(2), 166-176.

v. Demetriades, P. O., \& Law, S. H. (2006). Finance, institutions and economic development. International Journal of Finance and Economics, 11(3), 245-260.

vi. De Rose, V. J. L. (2017). A study on consumer preference towards e-Payments. International Journal of Advance Research in Computer Science and Management Studies [Special Issue], 5(2),(February), 5-9. Available online at: www.jjarcsms.com

vii. Dunne, P. J., \& Kasekende, E. (2016). Financial innovation and money demand: Evidence from Sub-Saharan Africa. South Africa: Economic Research Southern Africa (ERSA).

viii. Greenwood, J. \& Jovanovic, B. (1990). Financial development, growth and the distribution of Income. Journal of Political Economy, 98, 1076-1107.

ix. Hasan, I., De Renzis, T., \& Schmiedel, H. (2012). Retail Payments and Economic Growth, Bank of Finland Research Discussion Papers 19.

x. Hossein, K. H., \& Jaberi, R. (2009). The Impacts of Technical Changes on Banking Economic Indices, Case Study of Iran. Economic Review,14(24), 98-111.

xi. King, R., \& Levine, R. (1993). Finance and growth. Schumpeter might be right, Policy research. (Working papers,1083).

xii. Laeven, L., Levine, R. \& Michalopoulos, S. (2015). Financial innovation and endogenous growth. Journal of Financial Intermediation, 24(1), 1-24.

xiii. Loayza, V. N., \& Rancie're, R. (2006). Financial development, financial fragility, and growth. Journal of Money, Credit, and Banking, 38(4) (June), 1051-1076.

xiv. Moody's, (2016). The Impact of Electronic Payments on economic Growth, Moody's economy.com, (February). Available(www.economy.com).

xv. Norden, L., Buston, C. S., \& Wagner, W. (2014). Financial innovation and bank behavior: Evidence from credit markets. Journal of Economic Dynamics and Control, 43, 130-145.

xvi. Okoye, P. V. C., Ezejiofor, R. (2013). An appraisal of cashless economy policy in development of Nigerian economy. Research Journal of Finance and Accounting, 4(7), 237-252. 
xvii. Ouarda, M., \& Erlend, N. (2009). Payment Systems, Inside Money and Financial Intermediation, Paper presented at Bank of England, and IMF Conference, (July 14, 2009).

xviii. Rogers, E. (1995). Diffusion of Innovations. The Free Press, New York.

xix. Slozko, O., \& Pelo, A. (2014). The electronic payments as a major factor for further economic development. Economics and Sociology, 7(3), 130-140. Doi:10.14254/ 2071-789X.2014/ 7-3/13

xx. Wali, A., Wright, L. T. \& Reynolds, P. L. (2014). Cashless policy, users' perception and retail marketing performance. UK The Business \& Management Review, 5 (1), 101-111.

xxi. World Bank, (2014). Global Financial Development Report: Financial Inclusion, Washington. 